\title{
Revision total knee arthroplasty in the young patient: is there trouble on the horizon?
}

\author{
Vinay K Aggarwal \\ Rothman Institute of Orthopaedics, Thomas Jefferson University \\ Nitin Goyal \\ Rothman Institute of Orthopaedics, Thomas Jefferson University \\ Gregory Deirmengian \\ Rothman Institute of Orthopaedics, Thomas Jefferson University
}

Ashwin Rangavajjula

Thomas Jefferson University Medical School

Javad Parvizi MD

Rothman Institute Thomas Jefferson University

Follow this and additional works at: https://jjdc.jefferson.edu/rothman_institute

Part of the Orthopedics Commons

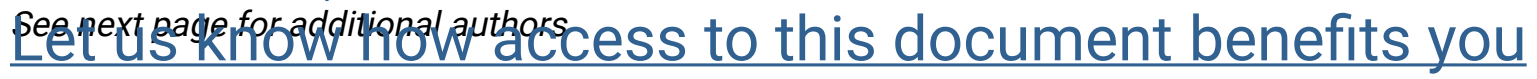

\section{Recommended Citation}

Aggarwal, Vinay K; Goyal, Nitin; Deirmengian, Gregory; Rangavajjula, Ashwin; Parvizi, Javad MD; and Austin, Mathew, "Revision total knee arthroplasty in the young patient: is there trouble on the horizon?" (2014). Rothman Institute Faculty Papers. Paper 45.

https://jdc.jefferson.edu/rothman_institute/45

This Article is brought to you for free and open access by the Jefferson Digital Commons. The Jefferson Digital Commons is a service of Thomas Jefferson University's Center for Teaching and Learning (CTL). The Commons is a showcase for Jefferson books and journals, peer-reviewed scholarly publications, unique historical collections from the University archives, and teaching tools. The Jefferson Digital Commons allows researchers and interested readers anywhere in the world to learn about and keep up to date with Jefferson scholarship. This article has been accepted for inclusion in Rothman Institute Faculty Papers by an authorized administrator of the Jefferson Digital Commons. For more information, please contact: JeffersonDigitalCommons@jefferson.edu. 


\section{Authors}

Vinay K Aggarwal, Nitin Goyal, Gregory Deirmengian, Ashwin Rangavajjula, Javad Parvizi MD, and Mathew Austin 


\title{
Revision Total Knee Arthroplasty in the Young Patient: Is There Trouble on the Horizon?
}

\author{
Vinay K. Aggarwal, MD, Nitin Goyal, MD, Gregory Deirmengian, MD, Ashwin Rangavajulla, BS, \\ Javad Parvizi, MD, FRCS, and Matthew S. Austin, MD \\ Investigation performed at the Rothman Institute of Orthopaedics at Thomas Jefferson University, Philadelphia, Pennsylvania
}

\begin{abstract}
Background: The volume of total knee arthroplasties, including revisions, in young patients is expected to rise. The objective of this study was to compare the reasons for revision and re-revision total knee arthroplasties between younger and older patients, to determine the survivorship of revision total knee arthroplasties, and to identify risk factors associated with failure of revision in patients fifty years of age or younger.
\end{abstract}

Methods: Perioperative data were collected for all total knee arthroplasty revisions performed from August 1999 to December 2009. A cohort of eighty-four patients who were fifty years of age or younger and a cohort of eighty-four patients who were sixty to seventy years of age were matched for the date of surgery, sex, and body mass index (BMI). The etiology of failure of the index total knee arthroplasty and all subsequent revision total knee arthroplasties was determined. Kaplan-Meier survival curves were used to evaluate the timing of the primary failure and the survivorship of revision knee procedures. Finally, multivariate Cox regression was used to calculate risk ratios for the influence of age, sex, BMI, and the reason for the initial revision on survival of the revision total knee arthroplasty.

Results: The most common reason for the initial revision was aseptic loosening (27\%; 95\% confidence interval $[\mathrm{Cl}]=19 \%$ to $38 \%$ ) in the younger cohort and infection (30\%; $95 \% \mathrm{Cl}=21 \%$ to $40 \%$ ) in the older cohort. Of the twenty-five second revisions in younger patients, $32 \%(95 \% \mathrm{Cl}=17 \%$ to $52 \%)$ were for infection, whereas $50 \%(95 \% \mathrm{Cl}=32 \%$ to $68 \%)$ of the twenty-six second revisions in the older cohort were for infection. Cumulative six-year survival rates were $71.0 \%(95 \% \mathrm{Cl}=60.7 \%$ to $83.0 \%)$ and $66.1 \%\left(95 \% \mathrm{Cl}=54.5 \%\right.$ to $80.2 \%$ ) for revisions in the younger and older cohorts, respectively. Infection and a BMl of $\geq 40 \mathrm{~kg} / \mathrm{m}^{2}$ posed the greatest risk of failure of revision procedures, with risk ratios of $2.731(p=0.006)$ and $2.934(p=0.009)$, respectively.

Conclusions: The survivorship of knee revisions in younger patients is a cause of concern, and the higher rates of aseptic failure in these patients may be related to unique demands that they place on the reconstruction. Improvement in implant fixation and treatment of infection when these patients undergo revision total knee arthroplasty is needed.

Level of Evidence: Therapeutic Level III. See Instructions for Authors for a complete description of levels of evidence.

Peer Review: This article was reviewed by the Editor-in-Chief and one Deputy Editor, and it underwent blinded review by two or more outside experts. It was also reviewed by an expert in methodology and statistics. The Deputy Editor reviewed each revision of the article, and it underwent a final review by the Editor-in-Chief prior to publication. Final corrections and clarifications occurred during one or more exchanges between the author(s) and copyeditors.

$\mathrm{T}$ 1 otal knee arthroplasty is a safe and effective procedure that is the surgical treatment of choice for advanced degenerative knee arthritis ${ }^{1}$. The volume of primary and revision total knee arthroplasties has increased by up to $200 \%$ over the past decade ${ }^{2-4}$. It is projected that, by the year 2030 , the number of total knee revisions in the United States will

\begin{abstract}
Disclosure: None of the authors received payments or services, either directly or indirectly (i.e., via his or her institution), from a third party in support of any aspect of this work. One or more of the authors, or his or her institution, has had a financial relationship, in the thirty-six months prior to submission of this work, with an entity in the biomedical arena that could be perceived to influence or have the potential to influence what is written in this work. No author has had any other relationships, or has engaged in any other activities, that could be perceived to influence or have the potential to influence what is written in this work. The complete Disclosures of Potential Conflicts of Interest submitted by authors are always provided with the online version of the article.
\end{abstract}

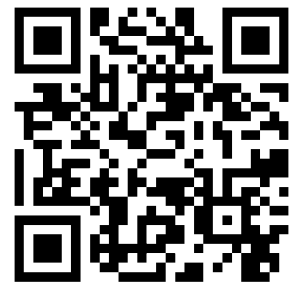

A commentary by Kelly G. Vince, MD, is linked to the online version of this article at jbjs.org. 
TABLE I Demographic Variables of Younger and Older Patient Cohorts

\begin{tabular}{|llll|}
\hline Demographic Variable & Younger Cohort & Older Cohort & P Value \\
\hline Age* $(y r)$ & & $62(46-69)$ & $<0.0001$ \\
At primary op. & $41(16-48)$ & $67(62-70)$ & $<.0001$ \\
At revision & $44(19-50)$ & 45 & 3.000 \\
Male $(\%$ of patients) & 45 & $32.4(21.5-54.2)$ & 0.808 \\
BMI* $\left(\mathrm{kg} / \mathrm{m}^{2}\right)$ & $32.1(19.7-57.6)$ & 95 & 0.674 \\
Osteoarthritis $(\%$ of patients) & 85 & $66(24-161)$ & 0.642 \\
Follow-up time* $(m o)$ & $69(24-140)$ & & \\
\hline *The values are given as the mean, with the range in parentheses. & & \\
\hline
\end{tabular}

grow approximately $600 \%$, to 268,200 cases per year ${ }^{3,5}$. Patients younger than sixty-five years of age are projected to contribute to the majority of this growth, accounting for $>55 \%$ of all total knee arthroplasties by the year $2030^{6}$. Specifically, demand from patients in the forty-five to fifty-four-year age group is expected to grow the fastest, reaching nearly one million total knee arthroplasties per year over the next twenty years ${ }^{6}$.

Fear of early failure and the need for subsequent revision surgery after primary total knee arthroplasty has led surgeons to consider a variety of non-arthroplasty surgical alternatives. These options, including realignment osteotomies, arthrodesis, and arthroscopic debridement, have been reported to have mixed results that tend to deteriorate with time ${ }^{7-9}$. There is literature suggesting that delaying total knee arthroplasty in younger patients with substantial pain and dysfunction can lead to inferior outcomes $^{10}$. There have been conflicting reports with regard to survivorship of primary total knee arthroplasties in younger patients. Some authors have noted comparable implant survivorship between younger patients and their older counterparts ${ }^{11-17}$. Other investigators have reported that younger individuals may have higher cumulative revision rates ${ }^{3,18-21}$.

In order to improve prosthetic survivorship in young patients after primary and revision surgery, the reasons for revision and failure of revisions must be clearly established. Several investigators have implicated both infection and aseptic loosening as the most frequent modes of failure among both older and younger patients ${ }^{18,22-26}$. Patients less than sixty years of age appear to be at increased risk for aseptic loosening, presumably because of their more active lifestyles ${ }^{20,23,27,28}$. Several studies have examined outcomes and survivorship following primary total knee arthroplasty in young patients, but few have assessed survival and reasons for failure of revision arthroplasties in young patients ${ }^{22,29}$.

The objectives of this study were to define the reasons for total knee arthroplasty in patients fifty years of age or less and to define the reasons for failure of the revision arthroplasty, determine the survivorship of revision total knee arthroplasty, and identify risk factors for failure of revision total knee arthroplasty in that population.

\section{Materials and Methods}

Tetrospectively reviewed the results of revision total knee arthroplasties
performed by six surgeons specializing in adult reconstruction at one institution over a ten-year time period (August 1999 to December 2009). Patients were identified for the study with use of our institutional prospective electronic database. A detailed chart review was performed for each patient. The date of and indication for the primary total knee arthroplasty, the etiology of the failure of the index arthroplasty, and the reason for and timing of all subsequent knee revision surgical procedures were noted. Details of all non-revision reoperations were also collected. Details of each operative procedure, including component specifics, were recorded and all complications were noted.

\begin{tabular}{|c|c|c|c|}
\hline & $\begin{array}{l}\text { Younger } \\
\text { Cohort }\end{array}$ & $\begin{array}{l}\text { Older } \\
\text { Cohort }\end{array}$ & $P$ Value \\
\hline \multicolumn{4}{|l|}{ 1st revision } \\
\hline Aseptic loosening & $23(27 \%)$ & $23(27 \%)$ & 0.853 \\
\hline Infection & $19(23 \%)$ & 25 (30\%) & 0.375 \\
\hline $\begin{array}{l}\text { Arthrofibrosis } \\
\text { (stiffness) }\end{array}$ & 12 (14\%) & $5(6 \%)$ & 0.121 \\
\hline Polyethylene wear & 9 (11\%) & $12(14 \%)$ & 0.637 \\
\hline Instability of joint & $8(10 \%)$ & $12(14 \%)$ & 0.470 \\
\hline $\begin{array}{l}\text { Extensor mechanism } \\
\text { failure }\end{array}$ & $6(7 \%)$ & - & - \\
\hline Other & $7(8 \%)$ & $7(8 \%)$ & - \\
\hline Total & 84 & 84 & - \\
\hline \multicolumn{4}{|l|}{ 2nd revision (re-revision) } \\
\hline Infection & $8(32 \%)$ & $13(50 \%)$ & 0.307 \\
\hline Aseptic loosening & 7 (28\%) & $4(15 \%)$ & 0.451 \\
\hline Arthrofibrosis & $4(16 \%)$ & - & - \\
\hline Other & $6(24 \%)$ & $9(35 \%)$ & - \\
\hline Total & 25 & 26 & - \\
\hline \multicolumn{4}{|l|}{$\begin{array}{l}\text { 3rd, 4th, and 5th } \\
\text { revisions }\end{array}$} \\
\hline Infection & 5 (63\%) & $3(50 \%)$ & - \\
\hline Aseptic failure & $3(38 \%)$ & $3(50 \%)$ & - \\
\hline Total & 8 & 6 & - \\
\hline
\end{tabular}


TABLE III Cumulative Six-Year Survivorship with 95\% Confidence Intervals in Younger and Older Cohorts

\begin{tabular}{|lccc|}
\hline & Overall & Septic Failure & Aseptic Failure \\
\hline Older cohort (\%) & $66.1(54.5-80.2)$ & $59.1(38.0-91.9)$ & $69.1(56.1-85.1)$ \\
Younger cohort (\%) & $71.0(60.7-83.0)$ & $57.4(38.8-84.9)$ & $75.6(64.5-88.7)$ \\
\hline
\end{tabular}

A younger patient study cohort and an older matched-patient control cohort were formed. Patients were included in the younger patient cohort if they had undergone their first revision of a total knee arthroplasty when they were fifty years of age or younger. Patients who were sixty to seventy years of age were identified from the database for the older cohort; they were then matched one-to-one for sex, body mass index (BMI), and date of surgery (year, month, and day were matched as closely as possible). The patients were matched for the date of surgery to approximately equalize the followup times, perioperative practices, and arthroplasty techniques and technology available at the time of surgery. All index procedures were primary total knee arthroplasties.

Patients who underwent unicompartmental knee arthroplasty as the index arthroplasty were excluded. We defined revision as removal or exchange of any prosthetic component for any reason in a patient with an existing total knee replacement. All patients had a minimum of twenty-four months of follow-up. In infected cases, the revision procedures consisted of irrigation and debridement with polyethylene exchange (four of twenty-five cases in the younger group and six of twenty-six in the older group), one-stage exchange arthroplasty (one of twenty-five cases in the younger group and one of twenty-six in the older group), or two-stage exchange arthroplasty (twenty of twenty-five cases in the younger group and nineteen of twenty-six in the older group). Antibiotic-impregnated cement was utilized in all revisions when a nonmodular component was replaced. Although we did not know the cement type used in each primary total knee arthroplasty, Simplex-P cement (Stryker, Mahwah, New Jersey) was used in $>75 \%$ of the revisions in which cement was employed. To ensure accuracy of survivorship data and minimize losses to follow-up, we contacted all patients by telephone in
December 2011 to complete data collection and to specifically inquire about revision surgery performed outside our institution. We contacted the families of patients who had died to assess the outcome of surgery at the time of death. During the time period identified more than 1500 total knee arthroplasty revisions were performed at our institution. Of these, 113 were done in patients fifty years of age or younger at the time of the revision. After exclusion of patients because of insufficient availability of data or lack of adequate followup, eighty-four knee revisions remained in the younger patient cohort. Eightyfour older patients were then matched as a control cohort (Table I).

Descriptive analysis was performed with use of the mean and frequency for continuous and categorical variables, respectively. Cumulative survival rates and associated $95 \%$ confidence intervals (CIs) were calculated with use of a Kaplan-Meier survival curve. The log-rank test was used to compare differences in cumulative survival rates between groups. The cumulative survival rate describes the risk of re-revision of a revision implant at a given time and was used instead of a crude revision rate (proportion of re-revisions to total number of revision knees included in the study). Cox proportional hazard regression was used to calculate the risk of re-revision. Age group (younger versus older), sex, $\mathrm{BMI}$, and reason for the initial revision (infection versus aseptic reasons) were all considered for their potential effect on cumulative survival rates and risk of revision failure in the study population. These factors were established as categorical variables with one category defined as a reference (relative risk of 1.0) and the other category compared with the reference by using Cox regression models.

\section{Source of Funding}

There was no external source of funding for this study.

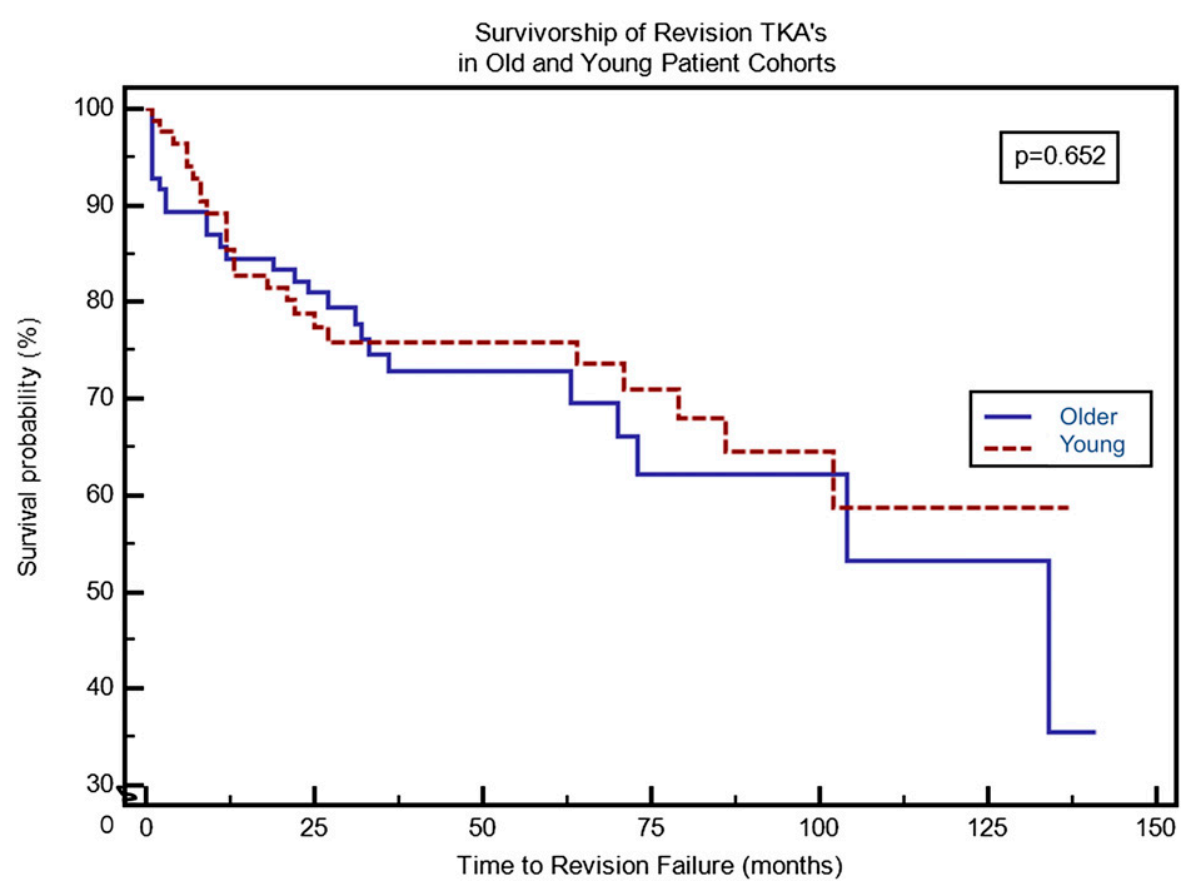

Fig. 1

No significant difference in implant survivorship was observed between older and younger patients after revision total knee arthroplasty (TKA). 
The Journal of Bone \& Joint Surgery $\cdot$ Jbjs.org VOLUMe 96-A • NUMBer $7 \cdot$ April 2, 2014
Revision Total Knee Arthroplasty in the Young Patient: Is There Trouble on the Horizon?

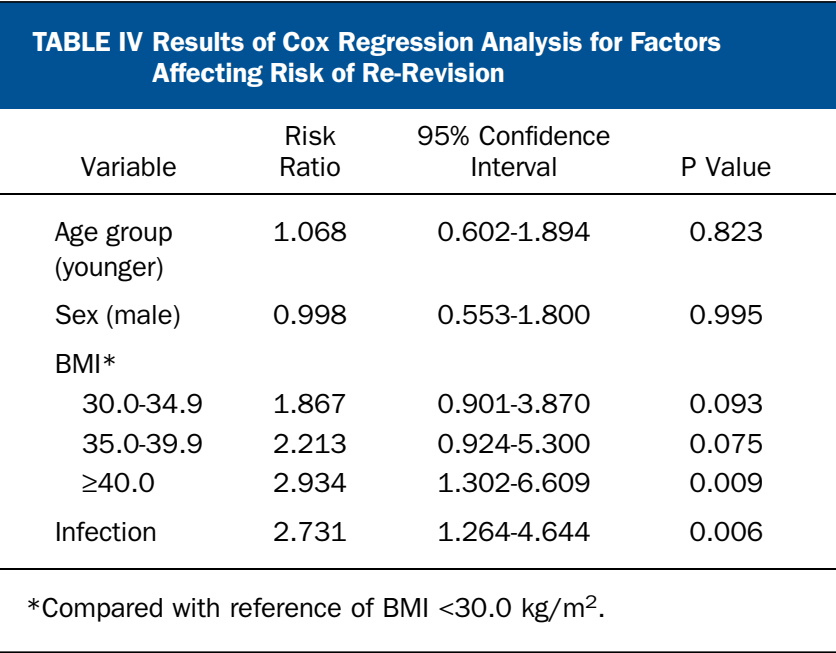

\section{Results}

7 he reasons for all revision surgical procedures are shown in Table II. There was an overall higher trend toward aseptic failures of both primary and revision total knee arthroplasties in the younger cohort; however, no significant difference between the older and younger groups was noted. Causes of primary and revision failures listed in the table as "Other" include delayed wound-healing, periprosthetic fracture, and extensor mechanism failure. The mean time from the index arthroplasty to the first revision in the younger cohort was thirty-six months (range, one to 210 months) compared with fifty-nine months (range, one to 230 months) in the older cohort $(\mathrm{p}=0.0028)$. The mean time from the first revision surgery to re-revision in the younger cohort was twenty-seven months (range, one to 102 months) compared with twentyeight months (range, one to 134 months) in the older cohort $(\mathrm{p}=0.7481)$.

The overall six-year cumulative survival rate for revision knee arthroplasties was $71.0 \%(95 \% \mathrm{CI}=60.7 \%$ to $83.0 \%)$ in the younger cohort and $66.1 \%(95 \% \mathrm{CI}=54.5 \%$ to $80.2 \%)$ in the older cohort (Table III). However, there was no significant difference in survivorship of revision total knee arthroplasty based on age group ( $\mathrm{p}=0.652$ ) (Fig. 1). In addition, patients with infection as the diagnosis at the initial revision procedure had a significantly lower cumulative survival rate after revision when compared with patients who had the initial revision surgery for reasons other than infection $(\mathrm{p}=0.0392)$ (Fig. 2). No other factors that were evaluated (sex, age, or further breakdown of the reasons for revision) significantly influenced the cumulative survival rate.

Cox regression analysis showed that patients with infection as the reason for the first revision were 2.7 times more likely to undergo re-revision than patients with aseptic causes ( $\mathrm{p}=0.006$ ). Furthermore, a BMI of $\geq 40.0 \mathrm{~kg} / \mathrm{m}^{2}$ was associated with a 2.9 times increased risk of re-revision $(\mathrm{p}=0.009)$. When age group, sex, and BMI groups of 30.0 to 34.9 and 35.0 to 39.9 $\mathrm{kg} / \mathrm{m}^{2}$ were considered, none were found to significantly increase the risk of re-revision (Table IV).

In our younger cohort, fifty-nine knees underwent one revision surgery, seventeen knees underwent two revisions, four underwent three, three underwent four, and one underwent five. Of the eight knees with three or more revisions, three

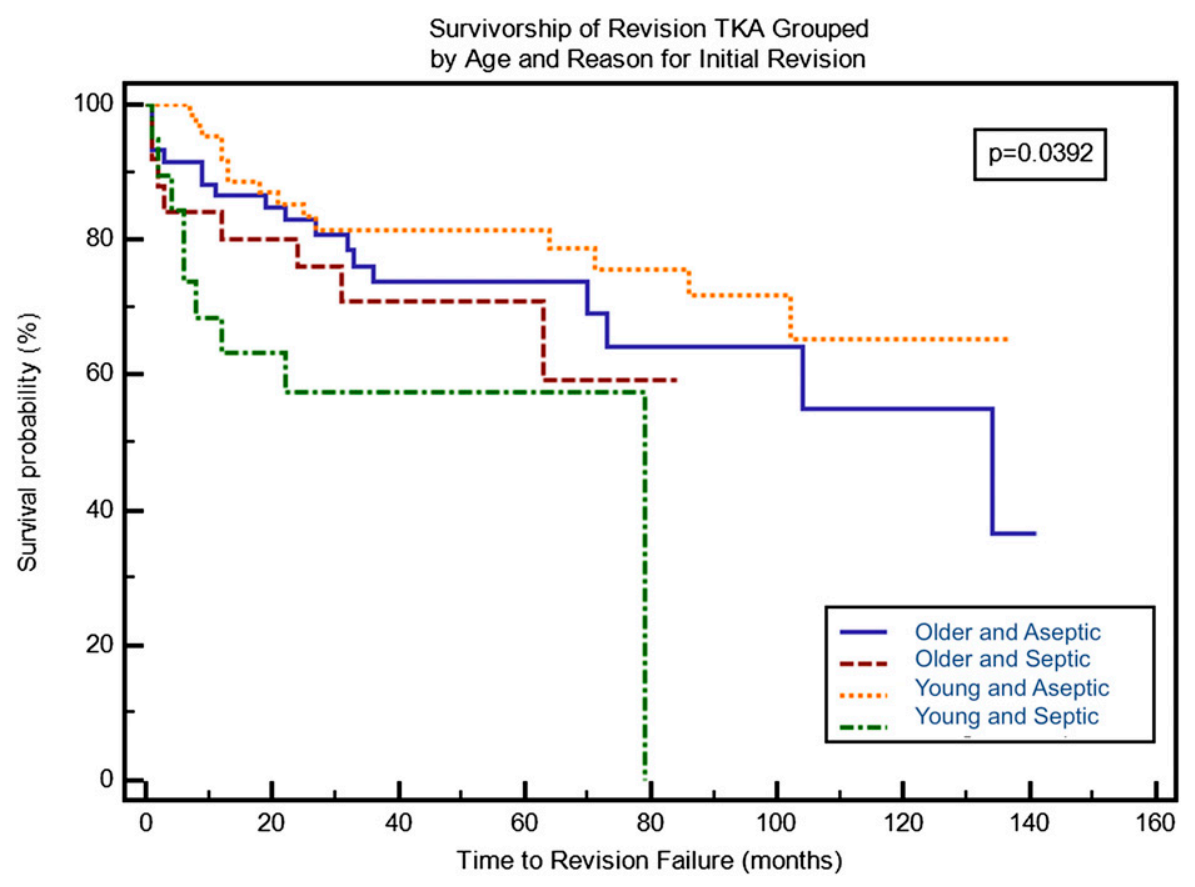

Fig. 2

Survivorship of revision total knee arthroplasty (TKA) grouped by age and reason for the initial revision. Infection led to worse survivorship of revision total knee arthroplasty in both age groups, with younger patients showing a greater difference between septic and aseptic failures. 


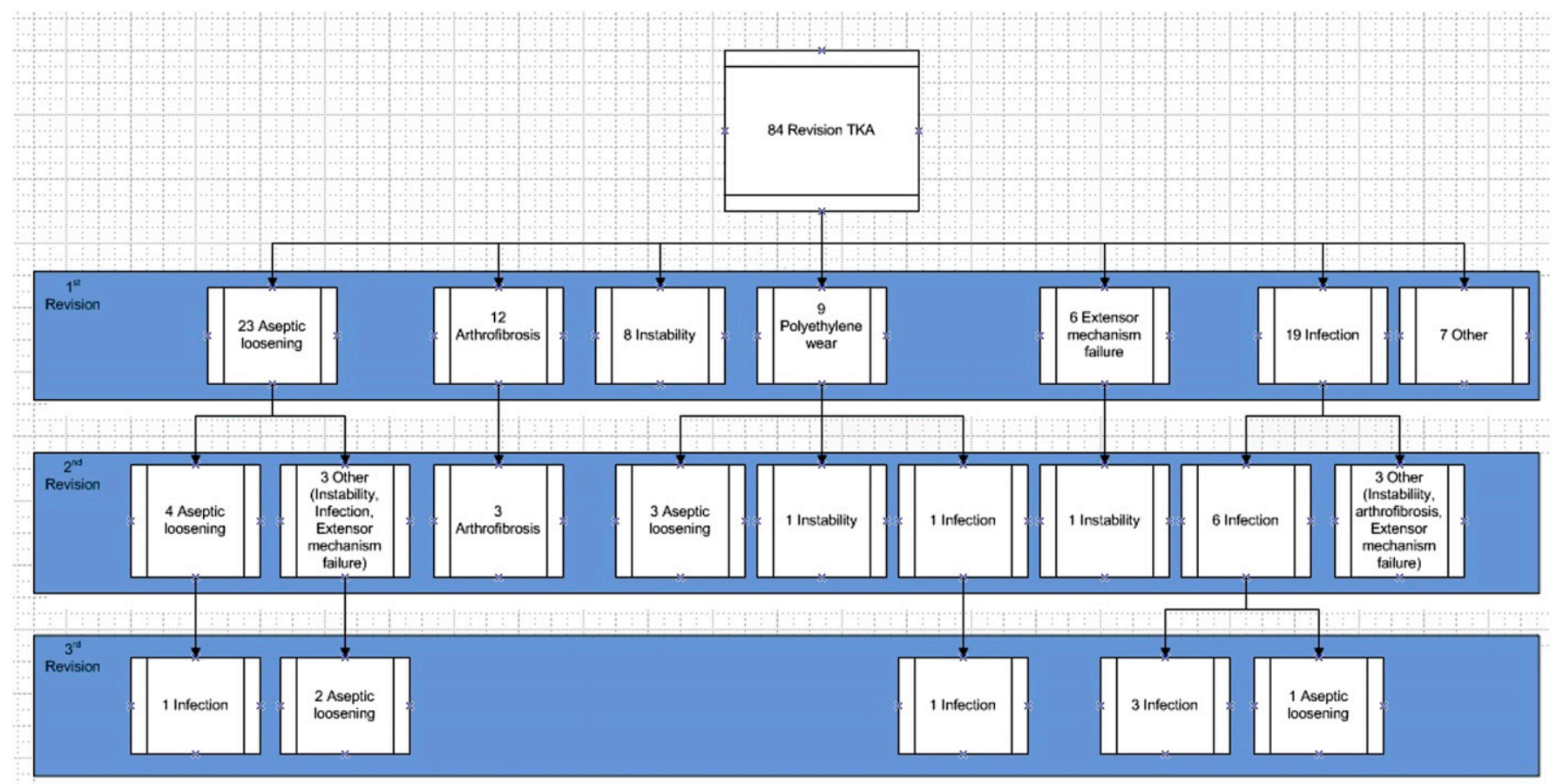

Fig. 3

Flowchart for the reasons for all revisions in the younger patient cohort. TKA $=$ total knee arthroplasty.

had the third revision because of aseptic loosening and five had it because of infection; one of the five had amputation secondary to infection (Fig. 3).

Seventy-six patients in the younger cohort had data on the constraint level of the first revision prosthesis: $41 \%$ of the prostheses were posterior stabilized, $58 \%$ were condylar constrained, and $1 \%$ were hinged. Seventy patients in the older cohort had data on the constraint level of the first revision prosthesis: $1 \%$ were cruciate-retaining, $20 \%$ were posterior stabilized, $74 \%$ were condylar constrained, and $4 \%$ were hinged (see Appendix). In the younger patient group, of the sixty-four revisions with femoral component replacement, sixty-three had sufficient information on implant design and fifty-four had sufficient information on fixation methods. Of the sixty-two revisions with tibial replacement, sixty-one had sufficient information on implant design and fifty-three had sufficient information on fixation methods. In the older patient group, of the seventy revisions with femoral component replacement, sixty-six had sufficient information on implant design and on fixation methods. Of the sixty-nine revisions with tibial replacement, sixty-five had sufficient information on implant design and on fixation methods.

\section{Discussion}

The incidence of total knee arthroplasty in young patients is increasing ${ }^{6}$. In order to improve the durability of the procedure, the failure mechanisms of primary and revision total knee arthroplasty in this population must be identified ${ }^{6}$. While authors of papers in the existing literature drew con- clusions about the failure modes of revision knee arthroplasty in all age groups, we believe that this young population may have unique revision failure modes that surgeons must take into account when considering surgical risks and fixation methods $^{30-32}$. The purpose of this study was to define the reasons for total knee arthroplasty revision and re-revision in patients fifty years of age or younger and determine the survivorship of revision total knee arthroplasty and isolate risk factors for failure of revision total knee arthroplasty in that population.

Our study is limited by its retrospective nature and by being based on the experience at a single institution. Based on the numbers of patients available for our study cohort, we are unable to draw any conclusions regarding survivorship of specific implant designs or knee fixation techniques used in younger patients-topics that undoubtedly warrant further investigation. Whereas prior studies have focused on only one particular subset of patients, our cohort comprised patients who underwent knee replacement in a tertiary referral center for an assortment of joint conditions, making the results more generalizable ${ }^{21}$.

In our study, the most frequent failure mode of primary total knee arthroplasty leading to the initial revision in the younger cohort was aseptic loosening $(27 \%)$, followed by infection (23\%) and arthrofibrosis (14\%). While some previous findings are in agreement with these results, several other studies, of patients with an older average age including that of the older patient cohort in our study, have shown infection to be the most common mode of failure of primary total knee 
The Journal of Bone \& Joint Surgery $\cdot$ Jbjs.org Volume 96-A · Number 7 • April 2, 2014
Revision Total Knee Arthroplasty in the Young Patient: Is There Trouble on the Horizon? arthroplasty ${ }^{18,23,26,30,32,33}$. Hossain et al., who reviewed 349 cases of revision total knee arthroplasty in patients with an average age of 67.8 years, reported periprosthetic infection as the cause of revision in $>30 \%$ of cases ${ }^{32}$. In perhaps the largest series of revision knee arthroplasties to date $(60,355$ in patients with an average age of 65.8 years), Bozic et al. found infection to be the reason for revision in $25.2 \%$ of cases ${ }^{33}$. Younger patients often have fewer comorbidities and higher activity levels compared with their older counterparts, possibly accounting for the higher proportion of aseptic loosening. There is little prior literature with which to compare the causes of revision failure and need for re-revision with those in our younger patient cohort. Although the finding was not significant, our younger cohort did show a higher proportion of aseptic failures of revision total knee arthroplasty compared with the older cohort, in which $50 \%$ of the revisions failed due to infection. Suarez et al. and Hossain et al. both found that infection led to a majority of revision failures ( $46 \%$ and $31 \%$, respectively), especially those failures that occurred earlier after surgery ${ }^{31,32}$. This likely affirms many surgeons' qualms about performing multiple surgical procedures on the same joint, as the risk of infection is greater with each subsequent procedure ${ }^{34,35}$.

Overall, our study showed a relatively poor six-year cumulative survivorship of revision total knee arthroplasties in the younger $(71 \%)$ and older $(66 \%)$ groups. This is substantially lower than the survivorship reported in previous studies of failure of revision knee arthroplasty in the overall community population. Hossain et al. reported a ten-year survivorship of $90.6 \%$, Suarez et al. reported a nine-year survivorship of $85 \%$, and Sheng et al. reported a ten-year survivorship from the Finnish arthroplasty registry of $79 \%{ }^{30-32}$. The mean ages in these three studies were sixty-six to sixty-nine years ${ }^{30-32}$. One of the possible reasons that our study did not show revision survivorship to differ significantly on the basis of age may have been the selection of a matched older cohort that was not old enough. It is plausible that only in elderly patient populations of more than seventy years of age does activity level decline enough to beneficially affect revision survivorship. This was shown by Sheng et al., who reported that patients who were more than seventy years old had significantly better revision survivorship than patients who were less than fifty-five years old and those who were fifty-five to seventy years old ${ }^{30}$.

Infection as the reason for the initial revision surgery was a significant predictor of poor implant survival in both groups, supporting the fact that current methods to treat and eradicate periprosthetic joint infection are inadequate and contribute to substantial morbidity years after an infection diagnosis. While it is out of the scope of this study to compare infection treatment techniques, including irrigation and debridement, one-stage exchange arthroplasty, and two-stage exchange arthroplasty, several reports in the literature suggest that two-stage exchange may be favored in place of simple singlestage procedures for infection ${ }^{36-38}$. No other reason for revision significantly impacted cumulative survival after knee revision.

With the growth in the rates of younger patients undergoing total knee arthroplasty, improving the relatively poor survivorship associated with primary and revision procedures will be vital. As we examined patients who had undergone revision over a decade through the year 2009, our cohort had a mix of patients with knee revisions performed with modern implant technology and fixation methods. While improving treatment for infection remains a focus, some surgeons are turning to use of porous-coated metaphyseal sleeves, trabecular metal cones, and traditional stems and augments to improve revision survivorship in these younger active patients ${ }^{39}$. With future studies specifically examining long-term outcomes after use of these relatively novel techniques, orthopaedic joint replacement surgeons must continue to be aware of the unique reasons for failure, including aseptic loosening, in patients under the age of fifty years.

\section{Appendix}

eA A table showing implant constraint level, implant design, eA and methods of fixation is available with the online version of this article as a data supplement at jbjs.org.

Vinay K. Aggarwal, MD

Nitin Goyal, MD

Gregory Deirmengian, MD

Ashwin Rangavajulla, BS

Javad Parvizi, MD, FRCS

Matthew S. Austin, MD

Rothman Institute of Orthopaedics at Thomas Jefferson University, Sheridan Building,

10th Floor,

125 South 9th Street,

Philadelphia, PA 19107.

E-mail address for V.K. Aggarwal: vinayagg1@gmail.com

\section{References}

1. Cram P, Lu X, Kates SL, Singh JA, Li Y, Wolf BR. Total knee arthroplasty volume, utilization, and outcomes among Medicare beneficiaries, 1991-2010. JAMA. 2012 Sep 26;308(12):1227-36, doi:10.1001/2012.jama.11153.

2. Kurtz SM, Ong KL, Schmier J, Zhao K, Mowat F, Lau E. Primary and revision arthroplasty surgery caseloads in the United States from 1990 to 2004. J Arthroplasty. 2009 Feb;24(2):195-203. Epub 2008 Apr 15, doi:10.1016/j.arth.2007. 11.015.

3. Kurtz S, Ong K, Lau E, Mowat F, Halpern M. Projections of primary and revision hip and knee arthroplasty in the United States from 2005 to 2030. J Bone Joint Surg Am. 2007 Apr;89(4):780-5, doi:10.2106/JBJS.F.00222.
4. Katz JN, Barrett J, Mahomed NN, Baron JA, Wright RJ, Losina E. Association between hospital and surgeon procedure volume and the outcomes of total knee replacement. J Bone Joint Surg Am. 2004 Sep;86-A(9):1909-16.

5. Centers for Disease Control and Prevention. NHIS arthritis surveillance. Arthritis prevalence in women and men. http://www.cdc.gov/arthritis/data_statistics/ national_nhis.htm\#future. Accessed 2011 Nov 30.

6. Kurtz SM, Lau E, Ong K, Zhao K, Kelly M, Bozic KJ. Future young patient demand for primary and revision joint replacement: national projections from 2010 to 2030. Clin Orthop Relat Res. 2009 Oct;467(10):2606-12. Epub 2009 Apr 10,

doi:10.1007/s11999-009-0834-6. 
The Journal of Bone \& Joint Surgery $\cdot$ JBjS. org VOLUme 96-A • NUmber 7 - April 2, 2014
Revision Total Knee Arthroplasty in the Young

Patient: Is There Trouble on the Horizon?
7. Hanssen AD, Stuart MJ, Scott RD, Scuderi GR. Surgical options for the middle-aged patient with osteoarthritis of the knee joint. Instr Course Lect. 2001;50:499-511. 8. Insall JN, Joseph DM, Msika C. High tibial osteotomy for varus gonarthrosis. A long-term follow-up study. J Bone Joint Surg Am. 1984 Sep;66(7):1040-8.

9. Nagel A, Insall JN, Scuderi GR. Proximal tibial osteotomy. A subjective outcome study. J Bone Joint Surg Am. 1996 Sep;78(9):1353-8.

10. Kennedy LG, Newman JH, Ackroyd CE, Dieppe PA. When should we do knee replacements? Knee. 2003 Jun;10(2):161-6.

11. Dalury DF, Ewald FC, Christie MJ, Scott RD. Total knee arthroplasty in a group of patients less than 45 years of age. J Arthroplasty. 1995 Oct;10(5):598-602.

12. Stern SH, Bowen MK, Insall JN, Scuderi GR. Cemented total knee arthroplasty for gonarthrosis in patients 55 years old or younger. Clin Orthop Relat Res. 1990 Nov;(260):124-9.

13. Diduch DR, Insall JN, Scott WN, Scuderi GR, Font-Rodriguez D. Total knee replacement in young, active patients. Long-term follow-up and functional outcome. J Bone Joint Surg Am. 1997 Apr;79(4):575-82.

14. Duffy GP, Trousdale RT, Stuart MJ. Total knee arthroplasty in patients 55 years old or younger. 10- to 17-year results. Clin Orthop Relat Res. 1998 Nov;(356):22-7. 15. Gill GS, Chan KC, Mills DM. 5- to 18-year follow-up study of cemented total knee arthroplasty for patients 55 years old or younger. J Arthroplasty. 1997 Jan;12(1):49-54. 16. Ranawat AS, Mohanty SS, Goldsmith SE, Rasquinha VJ, Rodriguez JA, Ranawat CS. Experience with an all-polyethylene total knee arthroplasty in younger, active patients with follow-up from 2 to 11 years. J Arthroplasty. 2005 Oct;20(7)(Suppl 3): 7-11, doi:10.1016/j.arth.2005.04.027.

17. Mont MA, Lee CW, Sheldon M, Lennon WC, Hungerford DS. Total knee arthroplasty in patients $</=50$ years old. J Arthroplasty. 2002 Aug;17(5):538-43.

18. Vessely MB, Whaley AL, Harmsen WS, Schleck CD, Berry DJ. The Chitranjan Ranawat Award: Long-term survivorship and failure modes of 1000 cemented condylar total knee arthroplasties. Clin Orthop Relat Res. 2006 Nov;452:28-34, doi:10.1097/01.blo.0000229356.81749.11.

19. Gioe TJ, Novak C, Sinner P, Ma W, Mehle S. Knee arthroplasty in the young patient: survival in a community registry. Clin Orthop Relat Res. 2007 Nov;464:83-7, doi:10.1097/BLO.0b013e31812f79a9.

20. Harrysson OLA, Robertsson 0 , Nayfeh JF. Higher cumulative revision rate of knee arthroplasties in younger patients with osteoarthritis. Clin Orthop Relat Res. 2004 Apr; (421):162-8.

21. Julin J, Jämsen E, Puolakka T, Konttinen YT, Moilanen T. Younger age increases the risk of early prosthesis failure following primary total knee replacement for osteoarthritis. A follow-up study of 32,019 total knee replacements in the Finnish Arthroplasty Register. Acta Orthop. 2010 Aug;81(4):413-9, doi:10.3109/

17453674.2010.501747.

22. Keeney JA, Eunice S, Pashos G, Wright RW, Clohisy JC. What is the evidence for total knee arthroplasty in young patients?: a systematic review of the literature. Clin Orthop Relat Res. 2011 Feb;469(2):574-83. Epub 2010 Sep 3, doi:10.1007/ s11999-010-1536-9.

23. Sharkey PF, Hozack WJ, Rothman RH, Shastri S, Jacoby SM. Insall Award paper. Why are total knee arthroplasties failing today? Clin Orthop Relat Res. 2002 Nov; (404):7-13.
24. Gonzalez MH, Mekhail AO. The failed total knee arthroplasty: evaluation and etiology. J Am Acad Orthop Surg. 2004 Nov-Dec;12(6):436-46.

25. Mulhall KJ, Ghomrawi HM, Scully S, Callaghan JJ, Saleh KJ. Current etiologies and modes of failure in total knee arthroplasty revision. Clin Orthop Relat Res. 2006 May;446:45-50, doi:10.1097/01.blo.0000214421.21712.62.

26. Fehring TK, Odum S, Griffin WL, Mason JB, Nadaud M. Early failures in total knee arthroplasty. Clin Orthop Relat Res. 2001 Nov;(392):315-8.

27. Insall JN, Binazzi R, Soudry M, Mestriner LA. Total knee arthroplasty. Clin Orthop Relat Res. 1985 Jan-Feb;(192):13-22.

28. Naudie DDR, Ammeen DJ, Engh GA, Rorabeck $\mathrm{CH}$. Wear and osteolysis around total knee arthroplasty. J Am Acad Orthop Surg. 2007 Jan;15(1):53-64.

29. Gioe TJ, Killeen KK, Grimm K, Mehle S, Scheltema K. Why are total knee replacements revised?: analysis of early revision in a community knee implant registry. Clin Orthop Relat Res. 2004 Nov;(428):100-6.

30. Sheng PY, Konttinen L, Lehto M, Ogino D, Jämsen E, Nevalainen J, Pajamäki J, Halonen P, Konttinen YT. Revision total knee arthroplasty: 1990 through 2002. A review of the Finnish arthroplasty registry. J Bone Joint Surg Am. 2006 Jul;88(7):1425-30, doi:10.2106/JBJS.E.00737.

31. Suarez J, Griffin W, Springer B, Fehring T, Mason JB, Odum S. Why do revision knee arthroplasties fail? J Arthroplasty. 2008 Sep;23(6)(Suppl 1):99-103. Epub 2008 Jun 5, doi:10.1016/j.arth.2008.04.020.

32. Hossain F, Patel S, Haddad FS. Midterm assessment of causes and results of revision total knee arthroplasty. Clin Orthop Relat Res. 2010 May;468(5):1221-8, doi:10.1007/s11999-009-1204-0.

33. Bozic KJ, Kurtz SM, Lau E, Ong K, Chiu V, Vail TP, Rubash HE, Berry DJ. The epidemiology of revision total knee arthroplasty in the United States. Clin Orthop Relat Res. 2010 Jan;468(1):45-51. Epub 2009 Jun 25, doi:10.1007/s11999-0090945-0.

34. Suzuki G, Saito S, Ishii T, Motojima S, Tokuhashi Y, Ryu J. Previous fracture surgery is a major risk factor of infection after total knee arthroplasty. Knee Surg Sports Traumatol Arthrosc. 2011 Dec;19(12):2040-4. Epub 2011 May 4, doi:10.1007/s00167-011-1525-x.

35. Kessler B, Sendi P, Graber P, Knupp M, Zwicky L, Hintermann B, Zimmerli W. Risk factors for periprosthetic ankle joint infection: a case-control study. J Bone Joint Surg Am. 2012 Oct 17;94(20):1871-6, doi:10.2106/JBJS.K.00593.

36. Teeny SM, Dorr L, Murata G, Conaty P. Treatment of infected total knee arthroplasty. Irrigation and debridement versus two-stage reimplantation. J Arthroplasty. 1990 Mar;5(1):35-9.

37. Fehring TK, Odum SM, Berend KR, Jiranek WA, Parvizi J, Bozic KJ, Della Valle CJ, Gioe TJ. Failure of irrigation and débridement for early postoperative periprosthetic infection. Clin Orthop Relat Res. 2013 Jan;471(1):250-7, doi:10.1007/s11999012-2373-9.

38. Romanò $C L$, Manzi $G$, Logoluso N, Romanò $D$. Value of debridement and irrigation for the treatment of peri-prosthetic infections. A systematic review. Hip Int. 2012 Jul-Aug;22(Suppl 8):S19-24, doi:10.5301/HIP.2012.9566.

39. Haidukewych GJ, Hanssen A, Jones RD. Metaphyseal fixation in revision total knee arthroplasty: indications and techniques. J Am Acad Orthop Surg. 2011 Jun; 19(6):311-8. 